\title{
UX Guideline for Children Educational Mobile Application: Pilot Case Study
}

\author{
Kiranjeet Kaur, Khairul Shafee Kalid, Savita K.Sugathan
}

\begin{abstract}
The growing technology today provides unlimited knowledge through smart gadgets. Mobile learning is getting popular among children nowadays. However, poorly designed mobile applications tends to diminish children's cognitive skills, which claims to be one of the most important skills in their developing process. User Experience $(U X)$ have been defined as the usability experience of a specific user while operating the mobile application yet, this concept has not been adopted while designing learning mobile application for children. UX claims to be an important aspect while designing a children mobile application for learning because children's experience differs from adults. Researchers have been highlighting on cognitive aspects when designing educational mobile application for children yet, there are no models or guidelines which can be referred by designers. Hence, this paper aims to enhance Experience- Centered Web Design Model by connecting a cognitive dimension. This study conducts a literature review to develop Enhanced Experience- Centered Web Design Model. A qualitative pilot case study has been conducted in order to amend all the necessary skills before conducting the actual case study method. It includes of semi-structured interview and observation method. The pilot study analysis will be referred for any amendments in interview questions and observation method to be further conducted for actual case study data collection of the study. The study will then develop an $U X$ guideline which would be referred by the mobile application designers when designing a children educational mobile application for learning environmental sustainability.
\end{abstract}

Index Terms: User Experience, cognitive dimension, children educational mobile application.

\section{INTRODUCTION}

Today, education is encouraging the community towards Science, Technology, Engineering and Mathematics (STEM) embracement and have a deeper appreciation value for progress while helping critical thinkers in nation to nurture. Nevertheless, the government is trying to educate the children more on sustainability. Thus, the mobile application content is for encouraging children to improve their understanding towards environmental sustainability. The content can also improve the children knowledge and their logical thinking skills to promote sustainable development through education.

Most of the researchers agree that using mobile gives an opportunity to the students as well as the teachers to facilitate an interactive and innovative teaching and learning process. Over the past few decades, several applied and theoretical research have combined the two new growing

Revised Manuscript Received on April 19, 2019.

Kiranjeet Kaur, Department of Computer Information Sciences,

Khairul Shafee Kalid, Department of Computer Information Sciences, Universiti Teknologi PETRONAS, Malaysia. Universiti Teknologi PETRONAS, Malaysia Universiti Teknologi PETRONAS, Malaysia

Savita K.Sugathan, Department of Computer Information Sciences,

communication technologies, mobile networks as well as the Internet yet; this combination is not well recognized as expected. Learning activities are practiced easily using mobile devices like mobile phones, handheld computers and tablets. As mobile devices are easily portable, accessing any educational content or material would be beyond the traditional classroom settings learning.

Technological development has introduced latest resources but at the end the user is who that decides to accept or reject the service. Thus, UX plays the role of one of the core concepts in the field of HCI even though the consent is uncertain. UX converges information, visual, web and content design, application architecture, visual rhetoric (image and branding), content creation and writing, and analysis (business, web, and "big data" analytics), among others [2].

Several ventures of defining, understanding and scoping UX has been done yet, there is no specific consensus which reached this concept [3]. Malaysia overleaps on promoting UX to home grown local software companies and mobile industries [1]. Hence, problem supporting this research content is cognitive dimension is not included while designing children educational mobile application. Cognitive dimension plays an important role in children's metal development stages but this dimension has been neglected while designing mobile applications for children Due to this, children's ability to solve critical problems is diminishing [2]. This paper refers to Experience- Centered Web Design (ECWD) Model [3], an UX model developed by Aaron Marcus from Design, User Experience, and Usability book that merges all the relevant information with theoretical elements of UX into three major elements which are aesthetic, functional and emotional. The study proposes to enhance the ECWD Model by including a cognitive dimension which will envision children's cognitive skills for integrating learning elements into the ECWD Model.

The objective of this paper is to enhance ECWD Model and conduct a pilot case study for amending all questions constructed before conducting the actual case study method. The pilot case study analysis will be considered to amend changes in the interview questions as well as observation method. Furthermore, this testing will be supporting the preliminary study to justify that the problem statement identified from literature review is applicable in real field of study. Enhancing ECWD Model contributes in achieving the research objectives which are (1) To identify elements of UX for children educational mobile application, (2) To validate the Enhanced ECWD Model and (3) To develop an 
UX guideline for children educational mobile application for learning environmental sustainability. In developing the guideline, a qualitative case study will be approached to conduct a semi-structured interview and observation method for the students to understand their experience in learning through mobile application. Their experience will be then incorporated in the UX guideline for the designer to be used when designing children mobile application.

\section{LITERATURE REVIEW}

\section{A. User Experience}

UX is a well-defined consequence of presentation, functionality, system performance, interactive behavior, and assistive capabilities of an interactive system for hardware as well as software [4]. UX has evolved into one of the core concepts of HCI where wide range of disciplines' researchers and practitioners daily work on these concepts. Despite several attempts of understanding, defining and scoping UX, no secured consensus has been reached on this concept [5]. Donald Norman was the first author who used the term "User Experience" to describe all the person's experience aspects with a system and he claims his introduction to the term UX as he believed "usability" to be narrowed deeply for representing a holistic vision of HCI [5]. According to Jacob Nielsen and Don Norman, UX encompasses "all aspects of the end-user's interaction with company, its services and its products" [6] yet not all associated with UX have agreed on this definition [7].

Generally, developers who are interested in UX design, not only focuses on what the product does but on how the users tend to interact with it. Thus, a positive experience requires substantial benefits to users and a negative experience entails frustration and failure [8]. Malaysia is still left out on promoting UX to home grown local software companies and mobile industries [1] also claim that software and mobile companies often focuses on product-oriented metrics. For example, pre-defined product goals are referred on creating operational goals and functional achievement.

According to [9], usability is unrestricted to design for high performance yet relevant information for users is involved. Thus, UX components are claimed as (1) perception of the instrumental qualities, (2) perception of the non-instrumental qualities and (3) emotional user interaction [10]. In this research the observation of children experiences and the factors that are creating interest barrier may lead to product changes. The three components which affects UX at the moment include: (1) system, (2) user and (3) context [3].

\section{B. Experienced-Centered Web Design Model}

The experience changes time to time when users interact according to the products' elements which are designed for creating specific experience [3]. The categories are associated in the dimensions of UX by referring to Experience- Centered Web Design Model. All the theoretical elements of UX have been discussed and merged into three dimensions in Experience- Centered Web Design Model. Fadel has done a comparative study on UX's axes then, associated with the similarities between categories and dimensions. The three dimensions which have been

finalized are emotional, aesthetic and functional as shown in Figure 1.

The emotional dimension claims to be the first dimension to be designed because the user experience will be conceived here [3]. The most individual and often idiosyncratic of human phenomena are probably emotions [11]. Overall interaction with mobile application is the focus of the study and the experience should be re-created, modified and amplified in real world. This dimension focuses on the user interactivity which enhances users' motivation through better participatory activity. Children's helping behavior emerges early in concrete operational stage, suggesting that pro sociality is rooted deeply in human nature [12].

The functional dimension deals with the mobile application's functionality and usability. The interface is portrayed into two perspective which are the clients and the users. The clients' perspective uses needs in relation to the interface where the general context of the application and clients' expectations are described. On the other hand, the users' needs in relation to the interface are gathered by interviewing them. The needs of clients and users are resumed as interface functionality where the interface actions are considered.

Aesthetic dimension contributes all visual attributes of the interface such as colors, texture, images and graphic composition. This aesthetic dimension actually represents the other two dimensions of UX. Picturing the concept and functionality may interest the user for experiencing the design [3]. In this paper, it is important that visibility, text, color, images, audio and animation can contribute a big portion to interactivity since, human respond better to visual arrangements. Research has confirmed that images prove to interest, create emotion and stimulate curiosity. Text needs to integrate with images since text create the meaning of the image. The animation is useful believed to catch the users' attention. This dimension proves to be useful to interactivity as human are highly sensitive to movement [3]. Planning the content of high visual aesthetic includes edutainment content for children and examination of the button and menus composed in proper sizes is crucial for children's physical characteristics as well as to reflect it in the content structure [13].

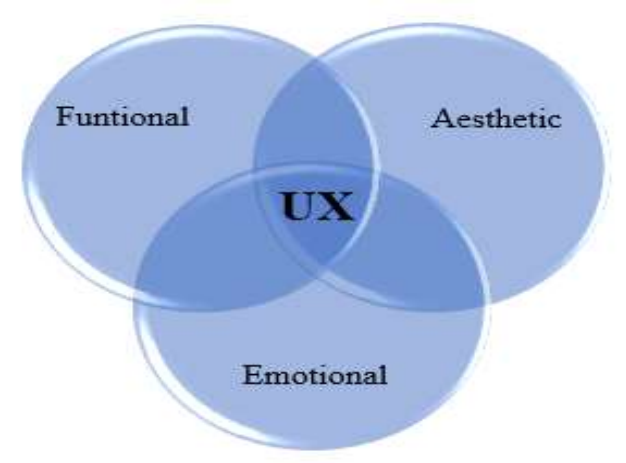

Fig 1: Experience- Centered Web Design Model [3] 


\section{Elements of $U X$}

There are several elements of UX discussed by various authors to address how important is to include cognitive dimension in designing mobile application. Every dimension has unique sets of elements that play unique role in their respective way. The user interface design or aesthetic plays a role of best beauty interaction [1] for users in order for them to accept the application because their dislikes could lead to anxiety or discomfort [14]. Fun as well as engaging interface design has motivated more students in learning [15]. The importance of functional dimension has been claimed as the clients' needs in relation towards the interface [3]. The anticipation a product usage or a system through a user's perception and responses is crucial [16] for a fun and engaging experiences [15]. Elements under functional dimensions has the credibility to compare and contrast the users' convenience, features and design of product [17] to attract targeted group of users for sustaining their loyalty [18].

Moreover, the elements under emotional dimensions generates its criticalness in UX by character interactivity users towards an interface and to what extend they can react to a user's interventions [3]. It is crucial to stress on this element due to users' complex and mixed feelings of emotions [16] during the interaction with the system or product [10]. The interaction between a user and the system may lead to unique experience in different context of use [19] which includes users perceptual and emotional aspects [4]. Cognitive defines level of ability which demands to master a specific information and technology literacy creatively as well as using innovative skills [20]. The representation of cognitive element in designing a system is important because it portrays a paradigmatic shifts of how a user anticipates about the interface [7] and the results will then represent usability of a system, product or service [16]. Nevertheless, cognitive helps to reduce complexity of an experience [4] by directing them to a right path of using the system [21]. Nevertheless, cognitive inclusive enhances users imagination and improves their behavior [22].

\section{Theories of Child Development in Education}

Today, psychologists have declared themselves with one of three general theoretical views which are cognitivedevelopment approach, the environmental/learning approach or ethological approach [23]. The cognitive- development approach was introduced by the developmental psychologist, Jean Piaget. Four basic concepts were used to elaborate the individual's cognitive structure activity process which are schema, assimilation, adaption and balance [24]. Schema which is the core concept of the structure has functions such as sorting, concluding, transforming as well as creating objective information for making sure the body is adaptable to environment effectively. Basically, cognitive development refers to the lifespan development of thinking. Thinking could be defined as problematic since, it has unclear boundaries that cold separate from other mental activities yet it involves higher mental processes such as problem solving, reasoning, creating, conceptualizing, categorizing, remembering and planning [25]. One of the most influential theory of cognitive development are Piaget's Theory of Cognitive Development.

Piaget's theory often focuses on the children's progress by referring to the development stages qualitatively [25]. According to Ellin Kotsky, Piaget's Theory occupied middle ground of two-level psychological function explanation. However, many researchers claim that Piaget and his challengers deliver different, pending perspective of the similar issues which has to be incorporated into cognitive development model [26]. In cognitive development, Jean Piaget's theory describes that children undergo through four mental development stages [27]. This theory not only focuses on understanding the way children obtain knowledge yet understanding the nature of intelligence. The stages in Jean Piaget's theory are sensorimotor stage (birth 2 years), preoperational stage $(2-7$ years $)$, concrete operational stage ( $7-11$ years) and formal operational stage (12 years - adult).

The sensorimotor stage, the infants establish an understanding of the world through coordinating sensory experiences like looking and hearing with physical movements as well as actions [28]. Infants interact with the environment by using their senses for understanding and interaction. The preoperational stage describes that children recognizes the world with images, words and drawings. Children begun to understand limited topological spatial relationships like separation, open/closed and proximity [29]. They develop the ability to represent mentally an object which does not exist [28].

The concrete operational stage characterized through logical thought of development [27]. Children at this stage tends to be very concrete, they grow to be more logical and sophisticated in their thinking in this stage. Describing the development of propositional logic in transition from the concrete thought of the child to the formal thought of the adolescent which the child at this stage cannot handle [30]. This stage includes genuine exercise of logic, resolving difficulties, reasoning, problems and undergo hindrances in a logical way. Usually, children in the concrete operational stage practice solving logical problems in their mind. For example, child can know as well as identify $\mathrm{A}>\mathrm{B}$ and $\mathrm{B}>\mathrm{C}$ but, he/she cannot understand the logical thinking way that $\mathrm{A}$ is also greater than C. Furthermore, feedback plays an important role in children's emotional dimension because the feedback which focuses on the correct stage of children reduces discrepancy between current understanding and what is desired [31]. Thus, the feedback from the application is the key that indicates performance changes in children and provides more interest in using it.

The basic characteristics of this stage are the logical stability of physical world, the factor of elements can be changed or transformed yet conserve several original characteristics; and able to see this change can be reserved [32]. Children can also identify objects according to the changes in the object size and classify them according to their shapes and colors. Children give full performance to concrete objects but is unable to handle abstract concept 
thus, the child is capable to associate with the things and the events in the environment. It is explained that children typically use their visual information for some guidance towards planned voluntary movements [33]. In this stage, it is also claimed that children are able to think in images much earlier than reading in written texts thus, providing pictures as well as voice menu along with text is a proper solution for avoiding the reading problems. As compared to the kids in the stage earlier they are more egocentric where else, children in this stage are more sociocentric [27].

The final stage of the Piaget's theory is formal operational stage where children's thinking is likely to be more sophisticated and advanced. Children in this stage are able to think about abstract and theoretical concepts as well as solving the problems creatively [27]. Skills of logical thought, deductive reasoning and systematic planning appears here.

\section{METHODOLOGY}

The methodology adapted in this study is divided into three sequential phases. The diagram below illustrates the stages with the following outcome.

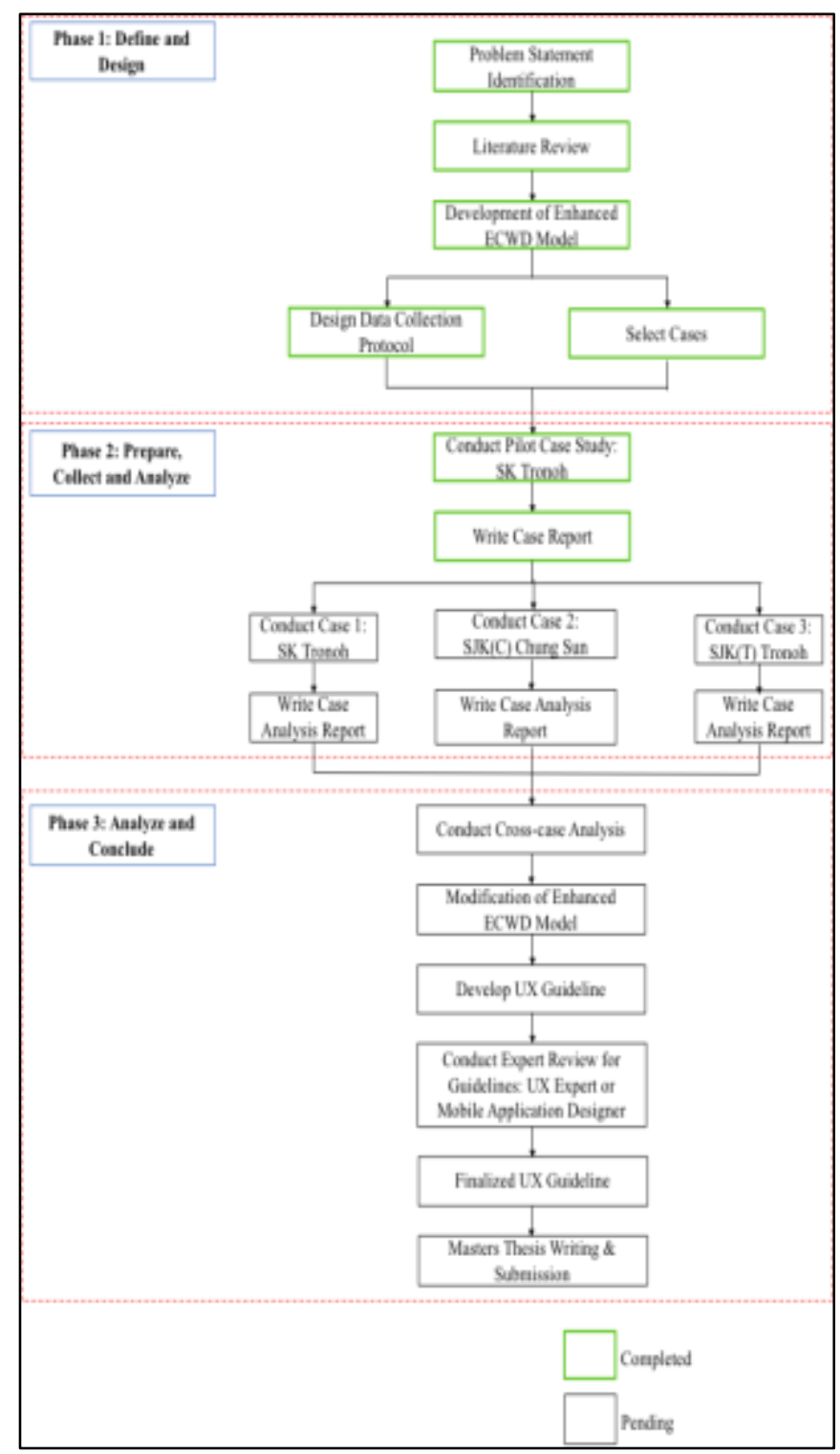

Fig 2: Research Activity

\section{Phase 1: Define and Design}

Qualitative approached is selected for this study since, it is useful to discover meaning which people give to events they experience. This study serves qualitative case study as the methodology. According to Robert E. Stake, case study methodology is defined as a strategy of inquiry where the researchers explore in-depth a program, event, activity, process or one or more individuals [34], [35]. Exploratory case study data collection method is used because it is often accompanied by additional data collection method(s) such as interview and observation. This study will be implementing cross-case analysis because is a method that facilitates the comparison of commonalities and differences in the events, activities, and processes; the units of analyses in multiple case studies [36].

There are five effective case study research design components by Robert Yin [37]: (1) research questions; (2) propositions or purpose of study; (3) unit analysis; (4) logic that links data to propositions; and (5) criteria for interpreting findings. The most suitable research question for case study are "how" and "why" forms of questions. Purpose of the study component are to identify elements of UX for children mobile application, to determine weightage of each UX elements and to develop an UX guideline for children mobile application. Unit analysis is defined as area of focus that case study will be analyzed [38]. This study's unit of analysis is the mobile application used in schools (cases to be studied). Thus, this study focuses on 3 cases which are Sekolah Kebangsaan Tronoh, SJK(C) Chung Sun and SJK(T) Tronoh.

This study's unit of analysis is the mobile application used in schools (cases to be studied). The mobile application version used is Android and the mobile applications are "Defender of Nature", "Environment Studies Guideline" and "Environment Current Affairs 2018 (offline)". These applications were selected accordingly since, the content in the app contributes with the "Kementerian Pendidikan Malaysia" syllabus, English language settings and Google Play ratings. The data collection method will be conducted through in-depth semistructured interviews and observation based on the Enhanced ECWD Model.

\section{Phase 2: Prepare, Collect and Analyze}

This section begins with the pilot case study after designing the cases and its content. For pilot case study, researcher decided to select the first case study, SK Tronoh. Researcher selected two individuals of standard 4 and 5 each for the semi-structured interview and observation session. Participants had undergone three sessions of the interview and observation due to the study wants to analyze 3 mobile applications. Firstly, the participants are handed a mobile device (Huawei Tablet) for observing their experience with "Defender of Nature" mobile application. Each observation takes 10 minutes and all the sessions are video recorded. After this method, participants undergo semi-structured interview questions which are based on the Enhanced 
ECWD Model for $20-25$ minutes. These sessions are repeated using different mobile application stated in the Phase 1 . The data are analyzed manually later on and it will be discussed in the discussion section.

The data collection then continues with the actual case studies after analyzing the pilot case study. Each of the cases will undergo only two session due to the researcher has eliminated the third mobile application since, the pilot case study analysis shows the same results. Thus, to avoid redundancy of data and to save some time the researcher concluded to use only "Defender of Nature" and "Environment Current Affairs 2018 (offline)". Moreover, only one participant at a time will be undergoing these

\section{Phase 3: Analyze and Conclude}

This is the section where the cross-case analysis will be conducted using In Vivo coding. Modification of the Enhanced ECWD Model will take place after analyzing the cross-case study. Once the model has been modified, an UX guideline will be developed and then will be delivered for expert review from an UX expert or mobile application designer. Later, modification of the UX guideline will be conducted referring to the expert's opinion. Thus, this will achieve this research objective to develop an UX guideline for children educational mobile application for learning environmental sustainability.

\section{RESULTS AND FINDINGS}

Literature review presents that there are several researchers who have been reviewing the elements for developing UX model. Researchers mostly discuss on the importance of UX elements and dimensions (functional, aesthetic, emotional and cognitive) which needs to be considered while designing an educational mobile application for children. After reviewing all the studies, this research has enhanced the ECWD Model by adding a cognitive dimension. Furthermore, each of the dimensions in the enhanced model illustrates that all the elements in each of the dimensions are important to be included because only the combination of those elements promises an optimistic user experience.

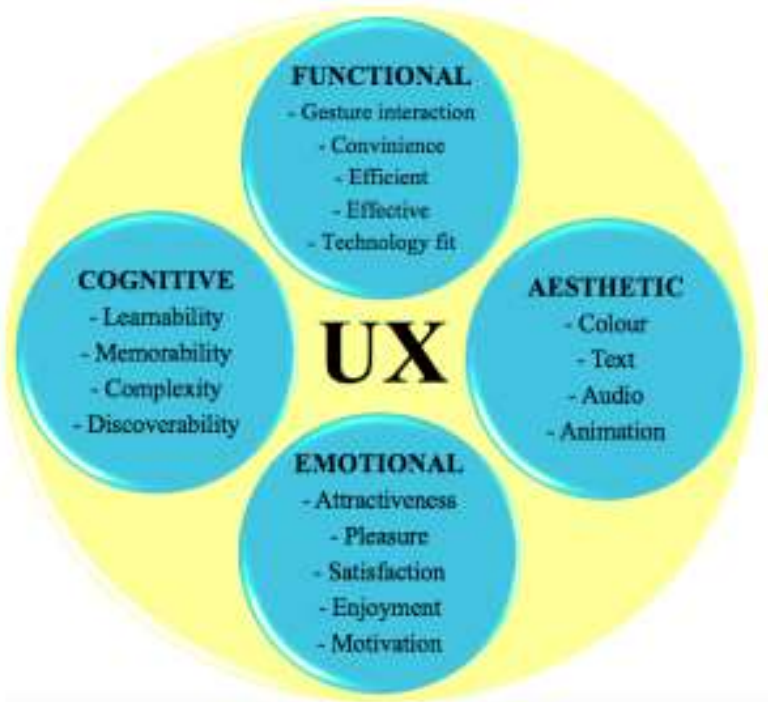

Fig 3: Enhanced Experience- Centered Web Development Model sessions instead of two.

The elements discovered in functional dimension are as shown as in Figure 3. Gesture interaction or normally refers as gesture-based interaction describes when the users tend to use their hand gesture while using the application [39]. Convenience refers to something that makes certain activities easier [40]. Efficient means operating quickly and results in a way user wants without any waste. Effective meant here is producing intended results while user is experiencing the mobile application. Technology fit means to what extend a technology assists an individual in performing users tasks. The elements which were uncovered in aesthetic dimension are also shown in the figure above. Colors in this dimension means the users encounters interesting qualities or details. Text is explained as sentences or any piece of writing that you study. Audio can be related with hearing, sound or music which is discovered in the application. Animation here refers to moving images that are photographed or created by computer.

The elements in emotional such as attractiveness means in this element is something that is causing interest in pleasant way. Pleasure meant here is something user wants from time to time to make them feel happy but is short-lived. Satisfaction which meant here is a pleasant feeling that a user gets when they receive something they wanted, or done something which they wanted to do. Enjoyment is a feeling of happiness and pleasure while using the app. Motivation is referred as enthusiasm for doing something willingly. While in the cognitive dimension there are also several elements which is defined in their own way. Learnability here refers to the speed and ease with which the user gets familiar with. Memorability is something which is likely to be remembered or worth remembering while using the application. Complexity has been referred as how the features of the application makes it difficult to understand. Discoverability here means the quality of users to easily find information in the mobile application.

There were two participants selected for this pilot case study who were both female. One participant was standard 4 and another participant was standard 5. In total, there were 3 sessions shared. Each sessions includes an interview session with both participants together and observation method. Each sessions lasted for 30 minutes. The findings from the interview sessions responses were almost similar for the educational mobile applications but game based mobile application responses were slightly different. As such, the themes are divided corresponding with the Enhanced ECWD Model dimensions which are functional, aesthetic, emotional and cognitive. The findings are further discussed through the themes and Appendix A provides the analyzed data of the interview sessions.

\section{Functional}

Participants responded that the icons which were displayed in all the three applications were well clear and easily visible. Moreover, they have also mentioned that the applications stages or pages move easily and fast to the new pages as well as they have not encountered any pop-ups throughout using the mobile applications. The participants 
have not encountered any errors and requires no loading when clicking on any icon or moving to other pages while using the app. A participant described how the application features works:

"The application responses very fast. It has no pop-ups or error while I use it."

\section{Aesthetic}

The participants described that they simply enjoy bright colors in the applications and they have also suggested some of their personal favorite colors to be added if there were given chance to. Both participants prefer the game to include multiple bright colors but prefer limited colors for the educational application.

"The colours are nice. But I want button other colour not same as behind colour. I want light blue for button cause then I can see better." As the second participant describes that "I like. I also want different colour if can because then can see more." For the educational application participant describes, "Ifeel dizzy if many colours when reading."

As for the sound the participants prefer sound and music only in the game and not in the educational because they claim it to be the factor of distraction for them. They have also claim that they prefer an educational application to present the information in paragraph writing form instead of only animation like storytelling, pictures and videos.

"I like the one like this app in paragraph because I think if it is not like this the information is not full. The space will be small to write more information if a lot of drawings and animation." Where else, the second participant, "I like in storytelling way cause it is not boring cause has many pictures and short words. I don't like to read a lot."

\section{Emotional}

The game application has a motivation factor to attract the participants to play more due to the sound effects, animation and colors but they find it a little boring when it comes to the educational application.

A participant respond when asked to use the app for 2 hours continuously, "I cannot read for 2 hours cause I feel dizzy but if got half storytelling and videos and only half paragraph then I can use. When I dizzy from reading I watch video. If only storytelling also I won't use 2 hours cause reading long make me dizzy." Another participant responded, "Not exactly. Because it will make me feel asleep."

\section{Cognitive}

Language response was highly stressed by the participants in the educational application because since, the application claims to be educating them in several ways which includes in improving their English proficiency thus, they suggested to have multiple language settings where they could understand difficult sentences meaning when they change language settings to Malay language. The participant have mentioned that the game relates to the content of Science which they have learnt in school but the educational application level of content is too complex for them to understand.

"No I can read but I don't understand because the word are hard and in Science I didn't see this all. I also need help from my parents to tell me what is the meaning but I don't ask help if I want to use it. I can go 'Back' and 'Exit' myself."

A semi-structured observation method was conducted initially before the interview session. These observation method was conducted to observe the participants using each of the applications for 10 minutes. This method will justify the necessity of the UX elements in practical usage. Thus, a checklist of all the Enhanced ECWD Model elements was developed to record all the observation which relates with each of the elements. Appendix B provides each of the observation data. The participants response overall was interactive with each other while using the applications. As for the game, participants enjoyed the overall experience yet, there were several tasks that were too complicatedly described or lack of instruction thus, the participants couldn't really manage to complete it and help was needed to do so. Where else, for the both educational applications the observed responses were quite similar. For example, the content of these applications were too complicated for them to even understand since, it does not cover the subjects taught in school. Overall, the observation sessions were conducted smoothly without any disruption.

\section{DISCUSSION}

The responses described by the participants in each of the sessions revealed the importance of executing each of the elements in Enhanced ECWD Model. Based on the interview and observation session, the participants have revealed how important is the application looks is to them and the appearance differs with the type of application. Participants uncovers that they prefer a game to present with bright colorful appearance but the prefer only limited colors for educational application. Furthermore, participants understanding has been neglected in both of the educational applications where the content of information is too complex for them to understand. Where else, the game recalls only limited environmental sustainability content which is throwing rubbish properly and not littering. The information environmental awareness is lacking in the game and on the other hand in educational app the information is too high level where the students can't seem to match the relativity of their learned subjects in school with the applications. Due to this, children tends to only focus on the emotional responses towards the game appearance and left behind on understanding the real contribution of these applications which is to create awareness of the importance of preserving the nature. Thus, this discussion response contributes in stressing on the problem statement which this research has investigated which is cognitive dimension is not included while designing children educational mobile application. Due to this, children's ability to solve critical problems is diminishing [2]. Hence, this contributes in achieving the research objective of validating the Enhanced ECWD Model. 


\section{CONCLUSION}

UX is a core concepts of HCI but it is not well utilized by the designers while developing mobile applications. This study had focused on conducting a pilot case study to validate the Enhanced ECWD Model before the actual data collection begins. The findings has contributed a positive result in supporting the research problem statement. There are several amendments which has been finalized by researcher in the interview questions for a better outcome in the next session of actual data collection. Furthermore, from the findings researcher recommends to conduct the sessions individually with each participants instead of as a pair to avoid similar answers. Since, children tends to copy the opinion of the other participant. Moreover, the application used has been limited to one game and one educational application instead of two. This is due to duplication of findings with the educational applications. The next stage of this research is conducting the actual case study data collection from the three case studies. The findings from the case studies will contribute in validating the Enhanced ECWD Model and to develop UX guideline which will be referred by the mobile application designers.

\section{ACKNOWLEDGMENT}

The authors would like to acknowledge the financial support from Universiti Teknologi PETRONAS graduate study scholarship.

\section{REFERENCES}

1. C. Y. Wong, K. Chu, and M. A. M. Pauzi, "Advocating UX practice in industry: Lessons learnt from UX innovate bootcamp," Proc. - 2016 4th Int. Conf. User Sci. Eng. i-USEr 2016, pp. 204-209, 2017.

2. R. S. Kraleva, "Designing an Interface For a Mobile Application Based on Children's Opinion," Int. J. Interact. Mob. Technol., vol. 11, no. 1, p. 53, 2017.

3. L. M. Fadel, "Experience-Centered Web Design Model," Springer Int. Publ. Switz. 2014 Int. Conf. Des. User Exp. Usability, vol. 8518, pp. 50-61, 2014.

4. F. Pucillo and G. Cascini, "A framework for user experience, needs and affordances," Des. Stud., vol. 35, no. 2, pp. 160-179, 2014.

5. C. Lallemand, G. Gronier, and V. Koenig, "User experience: A concept without consensus? Exploring practitioners' perspectives through an international survey," Comput. Human Behav., vol. 43, pp. 35-48, 2015.

6. D. Norman and J. Nielsen, "The Definition of User Experience (UX)," Nielsen Norman Group, 2016. [Online]. https://www.nngroup.com/articles/definition-userexperience/. [Accessed: 02-Jun-2018].

7. C. Mullins, "Responsive, Mobile App, Mobile First: Untangling the UX Design Web in Practical Experience," Proc. 33rd Annu. Int. Conf. Des. Commun. (SIGDOC '15), pp. 22:1-22:6, 2015.

8. C.-H. Park, G. Jang, and Y.-H. Chai, "Culturability in Mobile Data Services: A Qualitative Study of the Relationship Between Cultural Characteristics and UserExperience Attributes," Int. J. Hum. Comput. Interact., vol. 20, no. 3, pp. 285-303, 2006.

9. Aa. Marcus, Design, User Experience, and Usability. Springer International Publishing, 2011.

10. S. Mahlke and M. Thüring, "Studying antecedents of emotional experiences in interactive contexts," Proc.
SIGCHI Conf. Hum. factors Comput. Syst. - CHI '07, p. 915, 2007.

11. N. H. Frijda, The Laws of Emotion. 2013.

12. R. Hepach, "Prosocial Arousal in Children," Child Dev. Perspect., vol. 11, no. 1, pp. 50-55, 2017.

13. S. Park and D. Oh, "An Exploratory Study on the Content Design of Mobile Edutainment for Preschool Children," Int. J. Softw. Enginerring Its Appl., vol. 8, no. 11, pp. 55-66, 2014.

14. H. S. Al-Khalifa and R. A. Garcia, "Website Design Based on Cultures: An Investigation of Saudis, Filipinos, and Indians Government Websites' Attributes," Springer Int. Publ. Switz. 2014 Int. Conf. Des. User Exp. Usability, 2014.

15. S. A. Ariffin, "Needs and Potentials for Studying Local Malaysian Culture through Mobile Learning," Proc. 3rd Int. Conf. Human-Computer Interact. User Exp. Indones. - CHIuXiD '17, no. Mcmc, pp. 60-66, 2017.

16. V. Nagalingam and R. Ibrahim, "A Review of User Experience ( UX ) Frameworks for Educational Games," no. June, pp. 134-143, 2015.

17. S. H. Seol, D. S. Ko, and I. S. Yeo, "Ux analysis based on TR and UTAUT of sports smart wearable devices," KSII Trans. Internet Inf. Syst., vol. 11, no. 8, pp. 4162 4179, 2017.

18. A. Hussain, E. O. C. Mkpojiogu, N. M. Fadzil, and N. M. Hassan, "The UX of amila pregnancy on mobile device," AIP Conf. Proc., vol. 1891, 2017.

19. V. Nagalingam and R. Ibrahim, "Finding the right elements user experience elements for educational games," ACM Int. Conf. Proceeding Ser., vol. Part F1296, pp. 90-93, 2017.

20. Z.-T. Zhu, M.-H. Yu, and P. Riezebos, "A research framework of smart education," Smart Learn. Environ., vol. 3, no. 1, p. 4, 2016.

21. M. S. Patil et al., "UX design to promote undergraduate projects to products: Case study," Proc. - 2016 IEEE 4th Int. Conf. MOOCs, Innov. Technol. Educ. MITE 2016, pp. 302-307, 2017.

22. R. M. Yilmaz, "Educational magic toys developed with augmented reality technology for early childhood education," Comput. Human Behav., vol. 54, pp. 240 248, 2016.

23. V. Ross, M. M. Haith, and S. A. Miller, "PsycNET Record Display - PsycNET," Oxford, England: John Wiley \& Sons, 1992. [Online]. Available: http://psycnet.apa.org/record/1992-97080-000. [Accessed: 18-Jul-2018].

24. Q. Ni and Y. Yu, "Research on Educational Mobile Games and the effect it has on the Cognitive Development of Preschool Children," Third Int. Conf. Digit. Information, Networking, Wirel. Commun., pp. 165-169, 2015.

25. D. H. Feldman, "Cognitive development in childhood,' Handb. Psychol. Vol. 6, pp. 197-213, 2013.

26. S. Ellin Kotsky, "New Trends in Conceptual Representation: Challenges To Piaget's Theory - Google Books," Psychology Press, 2013. [Online]. Available: https://books.google.com.my/books?hl=en\&lr=\&id=24N qhCnc-

hkC\&oi=fnd $\& p g=P P 1 \& d q=$ piaget $\% 27 \mathrm{~s}+$ theory + of $+\operatorname{cog} n$ itive+development+comparison\&ots $=0$ iajXJa0yP\&sig $=F$ fjY5RWeeCmBr3KBw6Ni9TJZWO4\&redir_esc=y\#v=o nepage\&q=piaget's theory of cognitive development co. [Accessed: 07-Jun-2018].

27. K. Cherry, "Piaget's 4 Stages of Cognitive Development Explained," 2018. [Online]. Available: 
https://www.verywellmind.com/piagets-stages-ofcognitive-development-2795457. [Accessed: 02-Jun2018].

28. K. Ahmad, "Therapeutic Serious Game Design Guidelines for Stimulating Cognitive Abilities of Children With Speech and Language Delay," vol. 2, no. 2, pp. 284-312, 2017.

29. B. Yilmaz, "On the development and measurement of spatial ability," Int. Electron. J. Elem. Educ., vol. 1, no. 2, pp. 1-14, 2009.

30. B. Inhelder and J. Piaget, The growth of logical thinking from childhood to adolescence: An essay on the construction of formal operational structures. 2013.

31. J. Hattie and H. Timperley, "The power of feedback. [References]," Rev. Educ. Res., vol. .77, no. 1, pp. 16-7, 2007.

32. F. A. O. \& O. T.-O. Olabisi, "Counselling as an Enabling Tool for Quality Human Development: Challenges to Childhood Growth and Cognitive Development in the 21 st Century," Mediterr. J. Soc. Sci. MCSER Publ. RomeItaly, vol. 4, no. 3, pp. 317-322, 2013.

33. M. Paunescu, "NEUROPSYCHOLOGICAL LANDMARKS IN MIDDLE CHILDHOOD," $J$. Sport Kinet. Mov., vol. 2, no. 2, 2014.

34. P. R. Dodge, "Managing school behavior: a qualitative case study," p. 176, 2011.

35. T. Hollweck, "Robert K. Yin. (2014). Case Study Research Design and Methods (5th ed.). Thousand Oaks, CA: Sage. 282 pages.," Can. J. Progr. Eval., vol. 1, no. 2014, p. 4522, 2016.

36. D. S. Cruzes, T. Dybå, P. Runeson, and M. Höst, "Case studies synthesis: a thematic, cross-case, and narrative synthesis worked example," Empir. Softw. Eng., vol. 20, no. 6, pp. 1634-1665, 2015.

37. R. K. Yin, "Case Study Reserach - Design and Methods," Clin. Res., vol. 2, pp. 8-13, 2006

38. R. K. Yin, "Validity and generalization in future case study evaluations," Evaluation, vol. 19, no. 3, pp. 321332,2013

39. G. Luzhnica and E. Veas, "Investigating Interactions for Text Recognition using a Vibrotactile Wearable Display," pp. 453-465, 2018.

40. G. Ng-Kruelle, P. A. Swatman, D. S. Rebne, and J. F. Hampe, "The price of convenience: Privacy and mobile commerce," Q. J. Electron. Commer., vol. 3, no. January 2002, pp. 273-286, 2002.

\section{AUTHORS PROFILE}

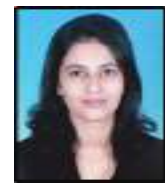

Kiranjeet Kaur is a MSc in Information System student from Universiti Teknologi PETRONAS. She has pursued her bachelor's degree in 2017. User experience and usability study is her current research interest. Kiranjeet's masters research is also on user experience contributing to children. She has attended one conference and intend to publish more work in journals in future.

Dr Khairul Shafee Kalid, a senior lecturer in Universiti Teknologi PETRONAS under Computer and Information Systems (CIS) department. He has been researching in depth in information systems and has completed his PHD in Information Technology in the year 2015. Knowledge management and the implication of big data in knowledge management is his current research. Dr Khairul has been actively publishing numerous papers in journals and conference proceedings in knowledge management field of area. Lastly, he has also been the principal investigator to two university research grants and two national level grants and a member to five other research project. Currently, he is undertaking the position of Postgraduate Coordinator in CIS department.

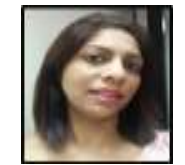

Dr. Savita K. Sugathan received her $\mathrm{PhD}$ in Information Technology from Universiti Teknologi PETRONAS, Malaysia in 2018, and her Master in Technology Management from University of New South Wales, Sydney, Australia in 2006. She is an academic staff in the Department of Computer and Information Sciences, Universit Teknologi PETRONAS, Malaysia since 2006. Recently, she has been accredited by Malaysia Board of Technologies (MBOT) as Professional Technologist (Ts.) in Information and Computing Technology (PT18050529). Dr. Savita has published research papers in leading international and national journals as well as conference proceedings such as International Journal of Information Systems and Supply Chain Management, Journal of Theoretical and Applied Information Technology, Advanced Science Letters, Advances in Intelligent Systems and Computing, 22nd Pacific Asia Conference on Information Systems and many more. Her research interest is on the Adoption, Implementation and Impact of Technology Advancements towards Sustainable Development which includes the fields of Education, Health and Manufacturing. 